\title{
Association between suppression of otoacoustic emissions and annoyance levels in tinnitus patients with normal hearing
}

\author{
Lucieny Silva Martins Serra \\ Ronaldo Campos Granjeiro ${ }^{2}$ \\ Silvia Cristina Lima Braga ${ }^{3}$ \\ Carlos Augusto Costa Pires de Oliveira \\ Andre Luiz Lopes Sampaio
}

\begin{abstract}
Objective: To correlate the annoyance of tinnitus assessed by the Tinnitus Handicap Inventory and on a visual analogue scale with the evoked otoacoustic emission test result in tinnitus patients with normal hearing. Study design: Case-control study. Setting: Public tertiary hospital. Subjects and methods: The sample was initially based on a population of 80 subjects with tinnitus; 20 of them had normal hearing and normal evoked otoacoustic emission test results and comprised the study group. For the purpose of comparison, a control group was formed, which consisted of 17 subjects with no hearing complaints and normal hearing. The participants were submitted to hearing tests, immittance testing and tests for the evaluation of acoustic reflexes, distortion product otoacoustic emissions, transient evoked otoacoustic emissions (TEOAEs), and suppression of TEOAEs. The tests were performed in a sound-treated booth using a linear contralateral noise of $60 \mathrm{~dB}$. The presence of suppression effects was defined when the response amplitude was $0.5 \mathrm{~dB}$ or higher. Results: Abnormal evoked otoacoustic emission suppression test results were observed in $52.9 \%$ of tinnitus patients and in $32.4 \%$ of control subjects $(p=0.086)$. Suppression effects of TEOAEs were absent in $38.5 \%$ of subjects with minimal or mild discomfort and in $61.9 \%$ of subjects with moderate or severe discomfort $(p=0.183)$. Conclusion: It was not possible to associate the annoyance caused by tinnitus with the TEOAE suppression test results, although suppression effects were found to decrease with increasing annoyance.
\end{abstract}

Keywords: tinnitus, quality of life, otoacoustic emissions, spontaneous.

\footnotetext{
${ }^{1}$ Universidade de Brasília - Brasília - DF - Brasil. E-mail: lucienymserra@gmail.com / cacpoliveira@brturbo.com.br / andremarjy@uol.com.br

${ }^{2}$ Escola Superior de Ciências da Saúde - Brasília - DF - Brasil. E-mail: ronaldogranjeiro@terra.com.br

${ }^{3}$ Secretaria de Saúde do Distrito Federal - Brasília - DF - Brasil. E-mail: sclbraga@gmail.com

Institution: Universidade De Brasília.

Send correspondence to:

Lucieny Silva Martins Serra

SQN 214 Bloco A Apt 303, Asa Norte - Brasília-DF - CEP: 70873-010

Paper submitted to the RBCMS-SGP (Publishing Management System) on November 15, 2015;

and accepted on December 24, 2015. cod. 215
} 


\section{INTRODUCTION}

Tinnitus is a sound perceived in one or both ears even in the absence of a sound stimulus, which directly affects the quality of life of individuals ${ }^{1-3}$. The annoyance caused by tinnitus has negative impacts on the life of affected individuals, reducing concentration and sleep and compromising emotional balance and social life. Patients with complaints of tinnitus indicate the annoyance of the symptom to be distressing. There are reports of attempted suicide as a result of the despair and disability caused by tinnitus. In some cases, tinnitus is more debilitating than hearing loss. About $20 \%$ of patients with tinnitus report significant annoyance associated with major impairment of quality of life ${ }^{4-7}$.

Tinnitus shows a strong association with hearing loss. However, about 10 to $20 \%$ of individuals with normal hearing thresholds have tinnitus in any time of life ${ }^{8-13}$. Several lines of research have been proposed to better understand the auditory pathway in tinnitus patients with normal hearing. One of these lines advocates that changes at central levels of the auditory system and in the efferent pathway, more specifically in the superior olivary complex, are one of the causes of tinnitus in normalhearing individuals, although the role of the efferent system in the etiology of tinnitus remains unclear ${ }^{14-16}$.

The human cochlea receives afferent innervation (eighth pair) and innervation of ipsi- and contralateral efferent fibers of the superior olivary complex (olivocochlear bundle). The efferent olivocochlear bundle is composed of two systems: the medial system, which innervates outer hair cells, and the lateral system, which innervates inner hair cells. These two systems influence the modulation of cochlear activity both by exciting and inhibiting it. The function of these systems can be measured through the suppression of evoked otoacoustic emissions ${ }^{17}$.

The otoacoustic emission (OAE) suppression test is an audiological test that assesses the efferent auditory system by investigating response amplitude suppression or changes in the latency and in the phase of EOAEs when a contralateral acoustic stimulus is introduced simultaneously to test recordings ${ }^{14}$. Suppression may be absent in cases of tinnitus, but its association with possible dysfunction in the medial efferent tract has not been confirmed.

The annoyance of tinnitus affects individuals in different ways. Thus, two patients may not perceive tinnitus in the same way, but all of them agree that the discomfort caused by it leads to anguish and despair ${ }^{17-19}$.

There are no studies in the literature establishing a correlation between the level of annoyance reported by tinnitus patients and the OAE suppression test. Therefore, the aim of the present study was to investigate the occurrence of this association.

\section{METHODS}

A case-control study was conducted at the Otolaryngology Department of Hospital de Base do Distrito Federal, city of Brasília, Brazil. The study was approved by the institutional Research Ethics Committee (Protocol No. 453.379).

\section{Sample}

The study sample was initially based on a population of 80 subjects with tinnitus and normal hearing determined by a hearing test. Next, OAE testing was performed and 20 subjects with normal results for distortion product otoacoustic emissions (DPOAEs) and transient evoked otoacoustic emissions (TEOAEs) were included in the study (tinnitus group). For the purpose of comparison, a control group was formed, which consisted of 17 subjects of both genders with confirmed presence of OAEs and no tinnitus complaints.

Subjects of both genders ranging in age from 20 to 60 years, who suffered from tinnitus, had normal hearing thresholds (up to $25 \mathrm{~dB}$ ) in all frequency bands tested, type A tympanometric curves and DPOAEs and TEOAEs, and signed the written consent form were included in the study. Exclusion criteria were audiometry tests showed hearing thresholds above $25 \mathrm{~dB}$ or abnormal OAEs, the presence of neurological disorders, drug treatment for tinnitus and ototoxic drug use.

\section{Procedures}

The participants were submitted to the following assessments: anamnesis and evaluation of tinnitus annoyance by the Tinnitus Handicap Inventory (THI) and on a visual analog scale (VAS). Next, the subjects underwent DPOAE and TEOAE testing.

Patients with normal OAE test results were submitted to OAE suppression testing. The ILO USB-V6 Clinical OAE system from Otodynamics Ltd. was used. For analysis of the suppression effect, an ipsilateral linear click presented at an intensity of $65 \mathrm{~dB}$ NPS was used as the evoking stimulus. The suppressor noise consisted of contralateral white noise stimulation at intensity of 60 dB NPS. This intensity is safe to prevent the activation of reflex mechanisms in the middle ear. The equipment possesses a semi-automated method in which samplings are presented alternately in the presence or absence of the suppressor noise at an interval of 3 seconds.

After the suppression procedure, the difference in TEOAEs in the presence or absence of the contralateral noise was analyzed for each ear according to specific frequency $(1,1.4,2,2.8$, and $4 \mathrm{~Hz})$ and overall response (provided by the equipment). A value higher than $0.5 \mathrm{~dB}$ was defined as a suppression effect as described by Velenovsky \& Glattke ${ }^{20}$. 
The data were analyzed and correlated using the SPSS 21.0 for Windows software. The results were tabulated and analyzed statistically using descriptive statistics and parametric (Student t-test) and nonparametric tests (Pearson's chi-square test). Levene's test was used to assess homogeneity of variances. The following analyses were performed: comparison of DPOAEs and TEOAEs and of the suppression effect of TEOAEs between the tinnitus and control groups; analysis of tinnitus annoyance and comparison with the TEOAE suppression test result, and trend analysis (ANOVA). A level of significance of $\leq 5 \%(p \leq 0.05)$ was adopted.

\section{RESULTS}

The tinnitus group consisted of 20 subjects aged 21 to 56 years (mean \pm standard deviation: $37.8 \pm$ 10.381 years). Thirty-four ears with tinnitus were studied, including $41.18 \%(n=14)$ of males and $58.82 \%(n=20)$ of females. The control group consisted of 17 subjects aged 22 to 57 years (32.41 \pm 7.34 years). Thirty-four ears were studied, including $35.3 \%(n=12)$ of males and $64.7 \%(n=22)$ of females. Since no significant differences were found in the distribution of ears between groups (Levene's test for homogeneity of variances = $2.74, p=0.107)$, the results were reported according to ear.

DPOAE analysis showed higher amplitudes (S/R) in the control group at frequencies of 1, 1.4, 2, 2.8 and 8 $\mathrm{kHz}$. Higher TEOAE amplitudes (S/R) were observed in the tinnitus group compared to control at all frequency bands tested, with a significant difference at the $1-\mathrm{kHz}$ frequency $(p=0.005)$ (Table 1$)$.

Table 1. Distribution of the amplitudes of transient evoked otoacoustic emissions in the tinnitus and control groups.

\begin{tabular}{llllccc}
\hline $\begin{array}{l}\text { Frequency }(\mathrm{Hz}) / \\
\text { Group }\end{array}$ & Mean & SD & Minimum & Maximum & $p$ \\
\hline \multirow{2}{*}{1000} & Tinnitus & 13.36 & 7.12 & -8.3 & 27.2 & $0.005^{*}$ \\
& Control & 18.50 & 5.99 & 4.3 & 28.3 & \\
\multirow{2}{*}{1400} & Tinnitus & 16.80 & 7.12 & -1.1 & 32.5 & 0.132 \\
& Control & 19.31 & 6.44 & 7.0 & 31.0 & \\
2000 & Tinnitus & 14.90 & 6.04 & 3.6 & 24.8 & 0.165 \\
& Control & 17.17 & 7.27 & 0.3 & 32.3 & \\
2800 & Tinnitus & 11.35 & 7.80 & -2.1 & 26.8 & 0.151 \\
& Control & 14.35 & 9.12 & -5.6 & 32.0 & \\
4000 & Tinnitus & 9.30 & 8.44 & -2.8 & 32.7 & 0.212 \\
& Control & 11.80 & 7.86 & -3.3 & 31.2 & \\
\hline \multirow{2}{*}{2.9}
\end{tabular}

*: Significant difference (Student $t$-test). SD: standard deviation.

The amplitudes of the DPOAE and TEOAE responses were also compared according to gender.
No significant differences were observed; however, the mean response amplitude was higher in females both in the control and tinnitus groups at all frequencies tested.

No significant differences in the overall suppression effect or in the values according to frequency band were observed between the two groups. In the tinnitus group, a suppression effect was present in $47.1 \%(n=16)$ of the subjects and was absent in $52.9 \%(n=18)$, while in the control group a suppression effect was present in $67.6 \%(n=23)$ and absent in $32.4 \%(n=11)$ (Table 2$)$.

Table 2. Analysis of the suppression effect of transient evoked otoacoustic emissions.

\begin{tabular}{|c|c|c|c|c|c|c|}
\hline \multirow[t]{2}{*}{ Suppression effect } & & \multicolumn{2}{|c|}{$\begin{array}{l}\text { Tinnitus group } \\
(\mathrm{n}=34)\end{array}$} & \multicolumn{2}{|c|}{$\begin{array}{l}\text { Control group } \\
\qquad(\mathrm{n}=34)\end{array}$} & \\
\hline & & Present & Absent & Present & Absent & \\
\hline \multirow{2}{*}{$\begin{array}{l}\text { Overall suppression } \\
\text { effect }\end{array}$} & $\mathrm{n}$ & 16 & 18 & 23 & 11 & \multirow{2}{*}{0.086} \\
\hline & $\%$ & $47.1 \%$ & $52.9 \%$ & $67.6 \%$ & $32.4 \%$ & \\
\hline \multirow{2}{*}{ Suppression $1 \mathrm{kHz}$} & $\mathrm{n}$ & 14 & 20 & 23 & 11 & \multirow{2}{*}{0.051} \\
\hline & $\%$ & $41.2 \%$ & $58.8 \%$ & $67.6 \%$ & $32.4 \%$ & \\
\hline \multirow{2}{*}{$\begin{array}{l}\text { Suppression } 1.4 \\
\mathrm{kHz}\end{array}$} & $\mathrm{n}$ & 20 & 14 & 24 & 10 & \multirow{2}{*}{0.447} \\
\hline & $\%$ & $58.8 \%$ & $41.2 \%$ & $70.6 \%$ & $29.4 \%$ & \\
\hline \multirow{2}{*}{$\begin{array}{l}\text { Suppression } 2.0 \\
\mathrm{kHz}\end{array}$} & $n$ & 18 & 16 & 22 & 12 & \multirow{2}{*}{0.460} \\
\hline & $\%$ & $52.9 \%$ & $47.1 \%$ & $64.7 \%$ & $35.3 \%$ & \\
\hline \multirow{2}{*}{$\begin{array}{l}\text { Suppression } 2.8 \\
\mathrm{kHz}\end{array}$} & $\mathrm{n}$ & 17 & 17 & 19 & 15 & \multirow{2}{*}{0.808} \\
\hline & $\%$ & $50 \%$ & $50 \%$ & $55.9 \%$ & $44.1 \%$ & \\
\hline \multirow{2}{*}{$\begin{array}{l}\text { Suppression } 4.0 \\
\mathrm{kHz}\end{array}$} & $\mathrm{n}$ & 13 & 21 & 17 & 17 & \multirow{2}{*}{0.464} \\
\hline & $\%$ & $38.2 \%$ & $61.8 \%$ & $50 \%$ & $50 \%$ & \\
\hline
\end{tabular}

n: number of ears. Pearson's chi-square test.

Regarding the discomfort caused by tinnitus and assessed by the THI, 38.2\% $(n=13)$ of the participants were classified as having minimal or mild tinnitus and $61.8 \%(n=21)$ as having moderate or severe tinnitus. There was no case of catastrophic tinnitus. Analysis of the discomfort caused by tinnitus on a VAS showed mild discomfort in $8.8 \%(n=3)$ of the subjects, moderate discomfort in $41.2 \%(n=14)$, and severe discomfort in $50 \%(n=17)$.

The correlation between the discomfort caused by tinnitus and the level of TEOAE suppression was also analyzed. Among subjects who reported minimal/ mild discomfort, 38.5\% $(n=5)$ exhibited no suppression effect of TEOAEs. Among subjects with mild/severe tinnitus, $61.9 \%(n=13)$ exhibited no suppression effect of TEOAEs. However, the difference between these two groups was not statistically significant (Table 3).

Although no significant correlation was found between the discomfort caused by tinnitus and $O A E$ suppression effects, the results were analyzed using tests for homogeneity of variances and trends. As can be seen 
Table 3. Association between the suppression effect of transient evoked otoacoustic emissions and tinnitus annoyance assessed by the Tinnitus Handicap Inventory in subjects of the tinnitus group.

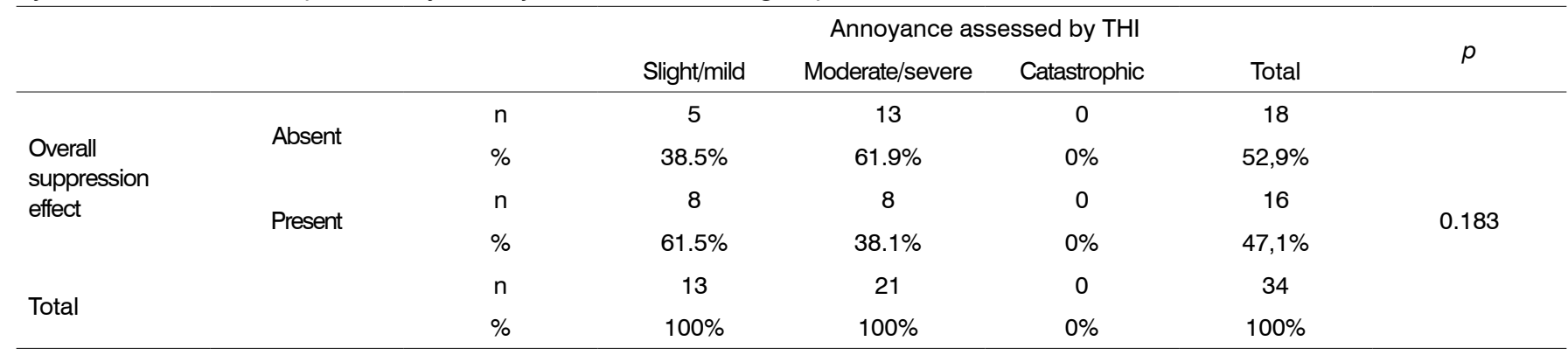

Chi-square test $=1.771, p=0.183$. THI: Tinnitus Handicap Inventory.

in Figure 1, the absolute values of the suppression effect decreased with increasing discomfort caused by tinnitus.

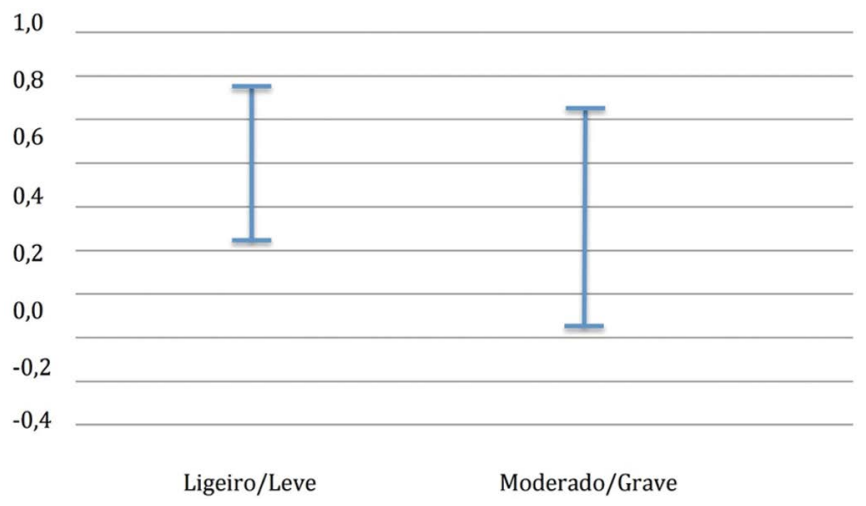

Figure 1. Trends of suppression effects according to tinnitus intensity assessed by the Tinnitus Handicap Inventory in subjects of the tinnitus group (ANOVA for trend analysis).

\section{DISCUSSION}

Tinnitus is a symptom that has major effects on many aspects of the life of affected individuals. The presentation of the symptom and the discomfort caused by it vary from case to case. A recent study published in The Lancet reported that tinnitus is more common in the left ear and usually progresses gradually, but a sudden onset may occur. In the present study, there was a predominance of bilateral tinnitus, and in cases of unilateral tinnitus the left ear was more frequently affected. Most participants of the tinnitus group $(70 \%)$ reported a sudden onset of the symptom ${ }^{4}$.

With respect to tinnitus periodicity, $80 \%$ of the subjects studied reported continuous tinnitus and $20 \%$ intermittent tinnitus. Sanchez et al. ${ }^{21}$ observed continuous tinnitus in $69 \%$ of cases and data from the Oregon Hearing Research Center $^{22}$ revealed the presence of continuous tinnitus in 85 to $90 \%$ of the subjects studied.

Cortina et al. ${ }^{23}$ investigated factors that improve and worsen the perception of tinnitus in 300 subjects with chronic tinnitus. Silence was reported to worsen tinnitus by $66 \%$ of the subjects, followed by nighttime $(61 \%)$ and anxiety (54\%). In the present study, silence was reported to worsen tinnitus by $70 \%$ of the patients and anxiety by $40 \%$. Most participants (90\%) reported tinnitus to get worse at night. Regarding factors that improve the symptom, in the study of Cortina et al. ${ }^{23}$, noise was mentioned by $38 \%$ of the participants and periods of rest by $26 \%$. In the present study, $30 \%$ of the patients reported background sounds (radio or TV) and music to improve tinnitus.

\section{Analysis of DPOAEs and TEOAEs in the groups}

Otoacoustic emissions are present in individuals with normal hearing thresholds and are no longer produced when the hearing loss is greater than $30 \mathrm{~dB}$. Changes in cochlear function are likely to be detected by the OAE test before the audiogram shows hearing loss ${ }^{24-26}$.

The risk of tinnitus is significantly increased in individuals with hearing loss. However, the annoyance caused by the symptom is not associated with the degree of hearing loss ${ }^{11}$.

About 10 to $20 \%$ of patients with tinnitus have normal hearing thresholds. There are no epidemiological studies investigating the percentage of subjects with tinnitus, normal hearing thresholds and OAE as done in the present study; however, on the basis of important studies such as those of Paglialonga et al. ${ }^{27}$ and Granjeiro et al. ${ }^{28}$, this number is believed to be small ${ }^{15}$.

Alterations in OAEs are more common in individuals with tinnitus compared to those without the symptom. Granjeiro ${ }^{25}$, studying a group of subjects with tinnitus and normal hearing, observed altered TEOAEs and DPOAEs in $61.8 \%$ of this group, while this percentage was $23.9 \%$ in the control group. In a similar study, Paglialonga et al. ${ }^{27}$ found altered DPOAE tests in $78 \%$ of subjects with tinnitus. The authors emphasized that DPOAEs were more sensitive in detecting outer hair cell dysfunction in individuals with tinnitus than TEOAEs.

The participants in the present study exhibited no changes in the DPOAE and TEOAE tests according to the protocol established in the methods section. Thus, the cochlear mechanism was completely or partly intact in this population. 
Although the presence of normal OAEs was used as an inclusion criterion in the present study, the OAE response amplitudes were lower in tinnitus patients than in the control group; however, this difference was not statistically significant in the DPOAE or TEOAE test, in agreement with the findings reported above.

Sato et al. ${ }^{29}$ and Miller ${ }^{30}$ reported greater OAE response amplitudes in females, a fact that might be due to differences in anatomical configurations between genders. In the present study, although not statistically significant, the amplitudes of the DPOAE and TEOAE responses were also greater in women both in the tinnitus and control groups.

\section{Suppression effect of OAEs}

The suppression of evoked OAEs is a test that can add value to the diagnosis of different diseases since it is a noninvasive and relatively rapid procedure to evaluate the efferent auditory pathway. We found no studies in the literature providing reference statistics regarding the occurrence of normal OAE suppression in normal-hearing adults, but some studies involving a control group reported data about the presence of a suppression effect.

In the case of individuals with tinnitus, several studies have investigated the correlation between the presence of tinnitus and the absence of suppression of evoked OAEs, but there is still no consensus about this association ${ }^{6,16,27,31-33}$.

The difficulty in verifying an association can be explained by the fact that tinnitus is a symptom of variable etiology which, in many cases, is multifactorial. It is therefore difficult for researchers to select a homogenous group of subjects with tinnitus for the development of studies.

Another factor that may have influenced data collection and analysis in studies investigating suppression effects is the lack of a well-established test protocol in terms of the type and intensity of the click and suppressor noise. Hood et al. ${ }^{34}$ investigated the suppression of OAEs by testing different intensities of the contralateral noise $(50,55,60,65$ and $70 \mathrm{~dB})$ and concluded that an association exists between the suppressor noise and active cochlear mechanisms and efferent function. However, it was not the objective of that study to establish protocols for clinical practice.

The protocol adopted in this study was chosen based on its possible reproducibility in future studies and its application with the equipment used for data collection.

Mor \& Azevedo ${ }^{16}$, studying OAEs and the olivocochlear system in subjects with tinnitus and normal hearing, observed no significant difference in the OAE response amplitudes between the tinnitus and control groups in terms of general responses or according to frequency band. There was also no significant difference in the occurrence of suppression effects between the two groups, although the suppression values were lower in tinnitus patients. A stimulus of about $80 \mathrm{~dB}$ and a suppressor noise of $60 \mathrm{~dB}$ were used ${ }^{16}$. The results of that study agree with the findings of the present study in which no significant difference was observed; however, suppression effects were less frequent in the tinnitus group (47.1\%) compared to the control group (67.6\%).

Riga et al. ${ }^{6}$ investigated the suppression of OAEs in 18 subjects with tinnitus and normal hearing. The protocol consisted of the evaluation of DPOAEs using a contralateral noise of $55 \mathrm{~dB}$. The authors found lower OAE response amplitudes in the tinnitus group compared to the group without the symptom, but the difference was not significant as observed in the present study.

Chéry-Croze et al. ${ }^{35}$ evaluated suppression of DPOAEs using a suppressor noise of $60 \mathrm{~dB}$. In contrast to the present study in which ears were analyzed independently, these authors performed an analysis according to subject and observed that in subjects with unilateral tinnitus the efferent system seemed less efficient on the side of the symptom since OAE suppression was lower in ears with tinnitus ${ }^{35}$.

Studying 30 subjects with tinnitus and a control group, Geven et al. ${ }^{32}$ observed no significant differences in the overall analysis of OAE suppression. The authors concluded that the amount of contralateral suppression was equal in tinnitus patients and control subjects, except for the 2.0- and 2.8-kHz frequency bands in the right ear for which tinnitus patients presented a lower suppression effect. The protocol consisted of TEOAE analysis using a stimulus of $65 \mathrm{~dB}$ and a contralateral noise of $70 \mathrm{~dB}$.

In the present study, no significant differences in the overall suppression effect were observed between groups, but there was a significant difference at the $1-\mathrm{kHz}$ frequency. Fávero et al. ${ }^{31}$ found a significant strong association between the absence of suppression and the presence of tinnitus in the frequency range of 1.5 to $4 \mathrm{kHz}$.

\section{Tinnitus annoyance and TEOAE suppression test}

The prevalence of tinnitus is high and this condition is the third worst symptom after severe and intractable pain and dizziness. The annoyance caused by tinnitus severely impairs the quality of life of about $2 \%$ of the population. Tinnitus annoyance also has socioeconomic consequences. Patients who require sick leave due to tinnitus are up to three times more likely to receive disability retirement than patients with other diseases ${ }^{36}$.

The annoyance caused by tinnitus does not seem to be related to factors such as gender, location of the symptom, age or hearing loss, and affects each 
individual in a different manner. Studies have reported that the annoyance of tinnitus decreases over time, suggesting that the patient becomes accustomed to the symptom ${ }^{37,38}$.

The objective of the present study was to verify the existence of a possible relationship between annoyance reported by patients with tinnitus and normal hearing and the TEOAE suppression test. Tinnitus patients exhibited a lower overall suppression effect and suppression according to frequency than control subjects. However, the difference between the overall results showed no significant association. The value of OAE suppression of tended to decrease as the level of annoyance caused by tinnitus increased. This finding provides further evidence of involvement of the efferent system in the generation of tinnitus.

Since tinnitus is a symptom of multifactorial origin and is often associated with other conditions, psychiatric aspects should also be taken into consideration. A large proportion of patients with tinnitus have anxiety and depression disorders associated with the symptom. The clinical evaluation of patients reporting annoyance of tinnitus should also include the assessment of mental state. Patients with tinnitus are more likely to develop symptoms of depression than those without tinnitus ${ }^{28}$.

In another study, Granjeiro et al..$^{25}$ demonstrated that tinnitus annoyance was not correlated with outer hair cell function when normal and altered TEOAEs and DPOAEs were evaluated. The authors suggested that, although cochlear dysfunction is a possible cause of tinnitus, it is not associated with the annoyance caused by the symptom. In that study, a significant association was found between the discomfort reported by tinnitus patients and anxiety and depression scores ${ }^{25}$.

The objective of the present study was to evaluate the relationship between tinnitus annoyance and suppression of OAEs, but not related psychiatric aspects. Studies in the literature have reported an association between tinnitus annoyance, anxiety, and depression.

Kehrle ${ }^{39}$ evaluated the level of annoyance in tinnitus patients with normal hearing thresholds and compared it to the results of the brainstem auditory evoked response test and to anxiety and depression scores. The authors concluded that tinnitus annoyance is not associated with normal or abnormal brainstem auditory evoked potentials (BAEPs), suggesting that dysfunction at the brainstem level is not related to annoyance. However, the authors found statistically significant results when anxiety and depression were analyzed. The results of that study demonstrated that the severity of tinnitus annoyance is associated with the severity of anxiety and depression disorders and not the auditory causes themselves ${ }^{39}$.

The present study and the studies of Granjeiro et al. ${ }^{28}$ and Kehrle ${ }^{39}$ suggest that the annoyance caused by tinnitus is not associated with outer hair cell function or BAEPs, and also does not seem to be related to dysfunction of the medial efferent system

In summary, suppression effects were absent in a considerable proportion of the tinnitus patients studied. However, this finding was also common in control subjects, with no significant difference between groups. The OAE suppression test only evaluates a small part of the efferent system, i.e., the medial olivocochlear system. The present study suggests that, although dysfunction of the medial efferent system is one of the theories accepted as an etiology of tinnitus, the changes found in this system do not seem to be related to the annoyance reported by the patients of this study.

It should be noted that there was a statistical trend indicating a decrease in the value of OAE suppression as the level of tinnitus annoyance increased.

It is possible that the protocol used in this study or even the OAE suppression test does not present adequate sensitivity and specificity to differentiate patients with tinnitus and controls. Further studies involving a larger sample of tinnitus patients with normal hearing in each annoyance category are needed, despite the difficulty in obtaining a homogeneous group of subjects with tinnitus and normal hearing thresholds and OAE tests.

The present results showed the lack of a significant correlation between the annoyance reported by tinnitus patients with normal hearing thresholds and the TEOAE suppression test result.

Most participants classified the discomfort caused by tinnitus as moderate/severe and none of the patients reported catastrophic tinnitus.

The TEOAE suppression test results were more frequently altered in tinnitus patients compared to control subjects, but the difference was not significant. The effect of supression tends to be less important as the annoyance increases.

This study did not receive any financial support.

\section{ACKNOWLEDGMENTS}

We thank Dr. Julival Fagundes Ribeiro, Director of Hospital de Base do Distrito Federal (HBDF), and Dr. Jader Reis Rebouças Filho, Head of the Otorhinolaryngology Service, HBDF, for permitting this study on the premises of the Hospital.

\section{REFERENCES}

1. Organização Pan-Americana da Saúde [Cited 2015 Aug 4]. Available from: http://www.paho.org/bra

2. The Royal National Institute For Deaf People [Cited 2013 Oct 10]. Available from: http://www.rnid.org.uk/information_resources

3. Esteves CC, Brandão FN, Siqueira CGA, Carvalho SAS. Audição, zumbido e qualidade de vida: um estudo piloto. Rev CEFAC. 2012;14(5):836-43. DOI: http://dx.doi.org/10.1590/S151618462011005000107 
4. Baguley D, McFerran D, Hall D. Tinnitus. Lancet. 2013;382(9904):16007. PMID: 23827090 DOI: http://dx.doi.org/10.1016/S0140$6736(13) 60142-7$

5. Holdefer L, Oliveira CA, Venosa AR. Group therapy for patients with tinnitus at the University of Brasília Medical School. Braz J Otorhinolaryngol. 2010;76(1):102-6. DOI: http://dx.doi.org/10.1590/ S1808-86942010000100017

6. Riga M, Papadas T, Werner JA, Dalchow CV. A clinical study of the efferent auditory system in patients with normal hearing who have acute tinnitus. Otol Neurotol. 2007;28(2):185-90. DOI: http://dx.doi. org/10.1097/MAO.0b013e31802e2a14

7. Lewis JE. Tinnitus and suicide. J Am Acad Audiol. 2002;13(6):339-41.

8. Oliveira CA, Venosa A, Araújo MF. Tinnitus program at Brasília University Medical School. Int Tinnitus J. 1999;5(2):141-3.

9. Martines F, Bentivegna D, Martines E, Sciacca V, Martinciglio G. Characteristics of tinnitus with or without hearing loss: clinical observations in Sicilian tinnitus patients. Auris Nasus Larynx. 2010;37(6):685-93. PMID: 20430549 DOI: http://dx.doi. org/10.1016/j.anl.2010.03.008

10. Elisabetsky M. Tratamento atual do zumbido. Rev Bras Otorrinolaringol. 1980;46(1):8-16.

11. Hiller W, Goebel G. Factors influencing tinnitus loudness and annoyance. Arch Otolaryngol Head Neck Surg. 2006;132(12):132330. PMID: 17178943 DOI: http://dx.doi.org/10.1001/ archotol.132.12.1323

12. Rosa MRD, Almeida AAF, Pimenta F, Silva CG, Lima MAR, Diniz MFFM. Zumbido e ansiedade: uma revisão da literatura. Rev CEFAC. 2012;14(4):742-54. DOI: http://dx.doi.org/10.1590/S151618462012005000009

13. Granjeiro RC, Kehrle HM, Bezerra RL, Almeida VF, Sampaio AL, Oliveira CA. Transient and distortion product evoked oto-acoustic emissions in normal hearing patients with and without tinnitus. Otolaryngol Head Neck Surg. 2008;138(4):502-6. DOI: http://dx.doi. org/10.1016/j.otohns.2007.11.012

14. Kehrle HM, Granjeiro RC, Sampaio AL, Bezerra R, Almeida VF Oliveira CA. Comparison of auditory brainstem response results in normal-hearing patients with and without tinnitus. Arch Otolaryngol Head Neck Surg. 2008;134(6):647-51. PMID: 18559734 DOI: http:// dx.doi.org/10.1001/archotol.134.6.647

15. Savastano M. Tinnitus with or without hearing loss: are its characteristics different? Eur Arch Otorhinolaryngol. 2008;265(11):1295-300. PMID: 18317787

16. Mor R, Azevedo MF. Emissões otoacústicas e sistema olivococlear medial: paciente com zumbido e sem perda auditiva. Pró-Fono. 2005;17(3):283-92.

17. Lonsbury-Martin BL, Martin GK, Telischi F. Emissões otoacústicas na prática clínica. In: Musiek FE, Rintelman WF. Perspectivas atuais em avaliação auditiva. Barueri: Manole; 2001. p.163-92.

18. Figuerêdo RBS, Corona AP. Influência do zumbido nos limiares auditivos de altas frequências. Rev Soc Bras Fonoaudiol. 2007;12(1):29-33. DOI: http://dx.doi.org/10.1590/S151680342007000100007

19. Oliveira JR, Fernandes CF, Costa Filho OA. Study on suppression of otoacoustic emissions: lateral domain. Braz J Otorhinolaryngol. 2011;77(5):547-54. PMID: 22030959

20. Velenovsky DS, Glattke TJ. Suppression of otoacoustic emissions in populations with normal hearing sensitivity In: Robinette MS, Glattke TJ, eds. Otoacoustic emissions: clinical applications. 3rd ed. New York: Thieme; 2007

21. Sanchez TG, Medeiros IRT, Levy CPD, Ramalho JRO, Bento RF. Tinnitus in normally hearing patients: clinical aspects and repercussions.. Braz J Otorhinolaryngol. 2005;71(4):427-31. DOI: http://dx.doi.org/10.1016/S1808-8694(15)31194-0

22. Oregon Hearing Research Center, 1981-1994 [Cited 2002 May 11]. Available from: http://www.ohsu.edu/xd/health/services/ent/ research/clinical-research/ent_clinical-trials.cfm
23. Cortina ME, Oliveira G, Boreli Filho F, Borilato ME, Fontoura ML, Royer $\mathrm{CP}$, et al. Prevalência de fatores de melhora e piora na percepção do zumbido em pacientes com zumbido crônico. Rev HCPA. 2007;27(supl1):1-292.

24. Kemp DT. Otoacoustic emissions in perspective. In: Robinette MS, Glattke TJ, eds. Otoacoustic emissions: clinical applications. New York: Thieme; 1997. p.1-21.

25. Granjeiro RC. Relação do incômodo do zumbido com a função das células ciliadas externas e os transtornos de ansiedade e depressão em indivíduos com limiar auditivo normal. [Tese de doutorado]. Brasília: Faculdade de Ciências da Saúde da Universidade de Brasília, 2011. 86p.

26. Durante AS. Emissões Otoacústicas. In: Bevilacqua MC, Martinez MAN, Balen SA, Pupo AC, Reis ACMB, Frota S. Tratado de Audiologia. São Paulo: Santos; 2011. p.145-58.

27. Paglialonga A, Del Bo L, Ravazzani P, Tognola G. Quantitative analysis of cochlear active mechanisms in tinnitus subjects with normal hearing sensitivity: multiparametric recording of evoked otoacoustic emissions and contralateral suppression. Auris Nasus Larynx. 2010;37(3):291-8. DOI: http://dx.doi.org/10.1016/j. anl.2009.09.009

28. Granjeiro RC, Kehrle HM, de Oliveira TS, Sampaio AL, de Oliveira $\mathrm{CA}$. Is the degree of discomfort caused by tinnitus in normal-hearing individuals correlated with psychiatric disorders? Otolaryngol Head Neck Surg. 2013;148(4):658-63. PMID: 23314160

29. Sato H, Sando I, Takahashi H. Sexual dimorphism and development of the human cochlea. Computer 3-D measurement. Acta Otolaryngol. 1991;111(6):1037-40. PMID: 1763623 DOI: http:// dx.doi.org/10.3109/00016489109100753

30. Miller JD. Sex differences in the length of the organ of Corti in humans. J Acoust Soc Am. 2007;121(4):EL151-5. PMID: 17471760 DOI: http://dx.doi.org/10.1121/1.2710746

31. Fávero ML, Sanchez TG, Bento RF, Nascimento AF. Contralatera suppression of otoacoustic emission in patients with tinnitus. Braz J Otorhinolaryngol. 2006;72(2):223-6. PMID: 16951856 DOI: http:// dx.doi.org/10.1016/S1808-8694(15)30059-8

32. Geven LI, de Kleine E, Free RH, van Dijk P. Contralateral suppression of otoacoustic emissions in tinnitus patients. Otol Neurotol. 2011;32(2):315-21. DOI: http://dx.doi.org/10.1097/ MAO.0b013e3181fcf180

33. Urnau D, Tochetto TM. Occurrence and suppression effect of otoacoustic emissions in normal hearing adults with tinnitus and hyperacusis. Braz J Otorhinolaryngol. 2012;78(1):8794. PMID: 22392244 DOI: http://dx.doi.org/10.1590/S180886942012000100014

34. Hood LJ, Berlin Cl, Hurley A, Cecola RP, Bell B. Contralateral suppression of transient-evoked otoacoustic emissions in humans: intensity effects. Hear Res. 1996;101(1-2):113-8. PMID: 8951438 DOI: http://dx.doi.org/10.1016/S0378-5955(96)00138-4

35. Chéry-Croze S, Collet L, Morgon A. Medial olivo-cochlear system and tinnitus. Acta Otolaryngol. 1993;113(3):285-90. PMID: 8517129 DOI: http://dx.doi.org/10.3109/00016489309135810

36. Langguth $B$. Tinnitus: the end of therapeutic nihilism. Lancet. 2012;379(9830):1926-8. DOI: http://dx.doi.org/10.1016/S01406736(12)60561-3

37. Folmer RL, Griest SE. Tinnitus and insomnia. Am J Otolaryngol. 2000;21(5):287-93. DOI: http://dx.doi.org/10.1053/ajot.2000.9871

38. Sanchez TG, Bento RF, Miniti A, Câmara J. Zumbido: características e epidemiologia: experiência do Hospital das Clínicas da Faculdade de Medicina da Universidade de São Paulo. Rev Bras Otorrinolaringol. 1997;63(3):229-35

39. Kehrle HM. Relação do incômodo do zumbido com os potenciais evocados auditivos do tronco encefálico e com os transtornos de ansiedade e depressão em indivíduos com limiar auditivo normal. [Tese de doutorado]. Faculdade de Ciências da Saúde da Universidade de Brasília, 2013. 22p. 